\title{
LANTANITA DE CURITIBA, PARANÁ
}

\author{
J. Moacyr V. Coutinho
}

(Departamento de Mineralogia e Petrografia, Universidade de S. Paulo)

\section{ABSTRACT}

Minute amethystine crystals of lanthanite were found covering fissure. surfaces of carbonate concretions in sedimentary pleistocene rocks at Curitiba, State of Parana. The crystals show platy (001) habit, bounded by very narrow (100) (010) (110) and (111) faces. Besides micaceous (001) cleavage,, two other parting (?) directions were also observed. The crystals are invariably twinned according to (110) plane. Four pairs cross groups are common. Optical data are given.

Some amount of rare earths of the cerium group may have been concentrated into ashes through prolonged plant decay. The lanthanite crystals would be the result of extration of lanthanum from ionic soil solutions, fixation on the surfaces of some colloidal body (psilomelane in case) and final crystallization.

Durante excursões efetuadas nos arredores de Curitiba, tivemos oportunidade de colher algumas amostras de rocha sedimentar, ondo pudemos verificar a ocorrência de pequenos cristais ametistinos de uma substância não identificavel no campo. Os estudos efetuados revelaram tratar-se de lantanita um mineral de terras raras do grupo do cério; $(\mathrm{La}, \mathrm{Di}, \mathrm{Ce})_{2}\left(\mathrm{CO}_{3}\right)_{3} .8 \mathrm{H}_{2} \mathrm{O}$

Por se tratar de mineral até hoje não mencionado no Brasil, e por apresentar algumas peculiaridades cientificamente interessantes, passamos a descreve-lo.

\section{Jazimento}

Os cristais se acham recobrindo uma superfície irregular de fratura em leitos secundários (concrecionais) de calcáreo argilo-arenoso das camadas pleistocênicas de Curitiba (5).

Os calcáreos da bacia de Curitiba caracterizam-se fàcilmente no campo, por se apresentarem em leitos irregulares esbranquiçados, próximos à superfície. São ainda porosos e friaveis, embora menos que os arenitos da mesma formação. 
O carbonato nas amostras se encontra sob a forma de calcita finamente granulada, cimentando grãos de origem clástica. Mas também pode a calcita formar cristais maiores e mais ou menos perfeitos em vesículas, ou ainda se recristalizar em granulação grosseira ao longo de fendas e outras aberturas das concreções.

Algumas provas rápidas, químicas e microscópicas, revelaram a existência de 15 a $25 \%$ de material detrítico contido nas concreções. A maior parte $( \pm 90 \%)$ desse resíduo é formada por quartzo e mineral argiloso, provavelmente montmorilonítico como faz crer sua baixa refringência e alta birrefringência. Há ainda pequena quantidade de feldspato predominando o plagioclásio oligoclásio sobre o feldspato alcalino. Minerais pesados em quantidade mínima, são raramente observados em lâmina. Foram identificados: turmalina, magnetita e anfibolio.

Preenchendo também finas fraturas nas concreções, ocorre abundantemente o manganês.

Os cristais de lantanita recobriam uma superfície rugosa e irregular interrompendo os filetes de calcita e manganês, comuns na rocha. Não se observou o mais leve sinal de movimentação ao longo daquela fratura.

\section{Morfologia}

Os cristais de lantanita se agregavam às paredes da fratura, sob a forma de rosetas, esferulitos, agregados cruciformes, grupos irregulares ou ainda, dispostos isoladamente. (figs. 2 e 3)

Os cristais examinados apresentavam-se com dimensões excessivamente pequenas para o estudo goniométrico. $O$ microscópio nos possibilitou confirmar a simetria rômbica bipiramidal dara pelos autores consultados ( 2 e 4$)$.

Os cristais se apresentavam em lâminas muito finas com apenas uma forma bem desenvolvida; a basal c (001) (fig 1) As outras faces: pinacoidais, a (100) e b (010); prismáticas $\mathrm{m}$ (110) e piramidais o (111) são finíssimas, com microns de largura e completam o contorno do cristal, dando-lhe um aspecto rômbico. As maiores placas não excediam as dimensões de: 

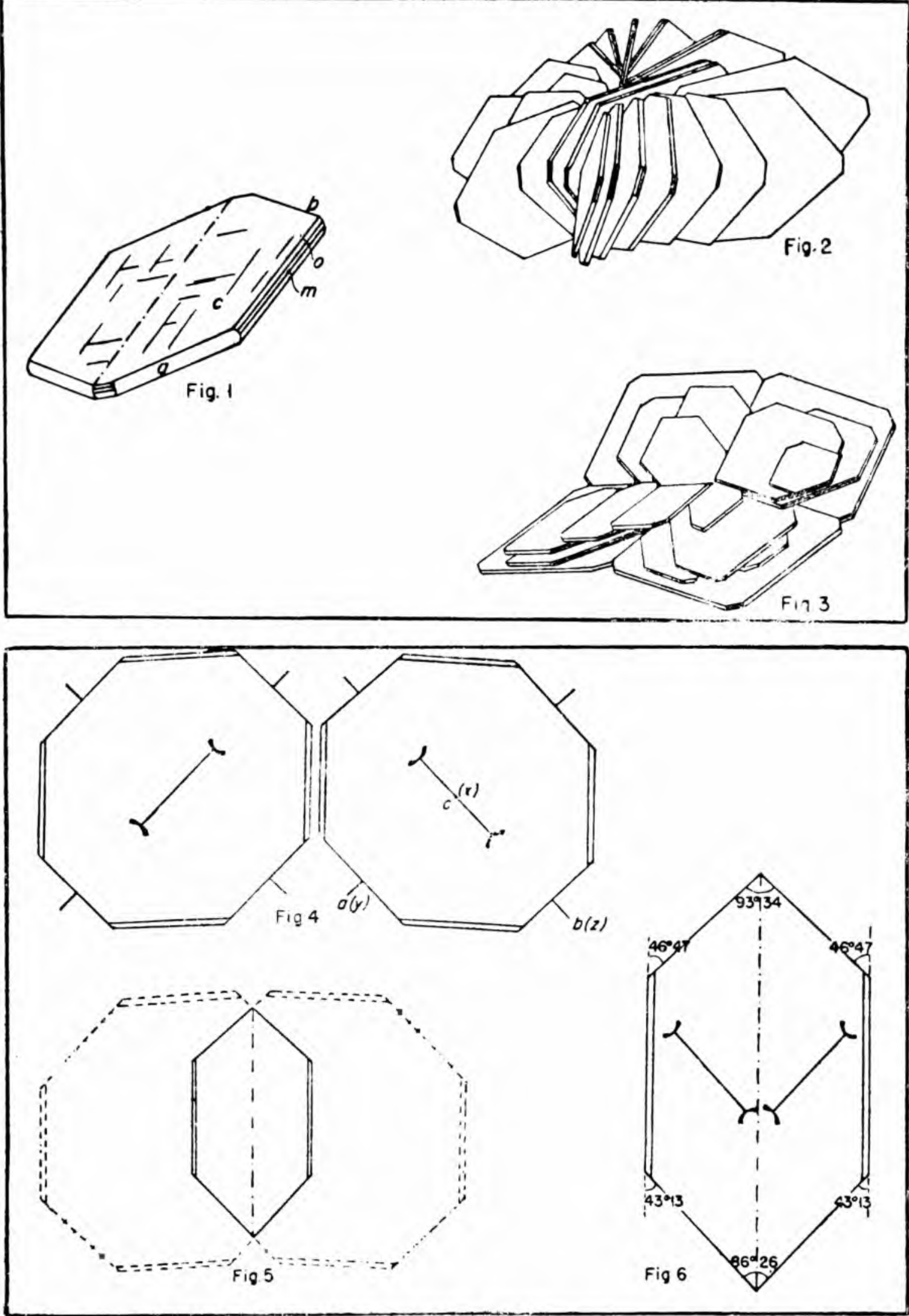
$1 \mathrm{~mm}$ de comprimento

0,7 a $1 \mathrm{~mm}$ de largura

0,01 a $0,04 \mathrm{~mm}$ de espessura

A espessura pode ser até quintuplicada se considerarmos que normalmente são encontrados varios cristais laminares superpostos paralelamente. (fig 3)

Além da clivagem basal micácea, observamos duas outras direções de facil separação (fig. 1), aproximadamente a $90^{\circ}$ uma da outra e correspondentes à forma (110) Esta clivagem não se acha consignada nos texitos consultados.

Os cristais são invariavelmente geminados em pares (fig 1 e 6 ). A face de geminação e contacto é também a do prisma (110) Entretanto o fenómeno só pode ser claramente verificado ao microscópio, já que à lupa não se observam ângulos reentrantes. Apenas tênue linha, coincidindo com o maior diametro do polígono, nos faz prever alí um plano de geminação.

O indíviduo isolado (rômbico holoédrico) de pseudo-simetria tetragonal, quando geminado em pares, mostra uma pseuso-simetria rômbica (fig. 6) A explicação do fato não é dificil se admitirmos os indivíduos isolados com cortono octogonal formado pelas faces: (100), (010) e (110), todas fazendo entre sí, ângulos variando pouco de 45') (100) $\angle(110)=43^{\circ} 13^{\prime} ;(110) \angle(010)=46^{\circ} 47^{\prime}$ A geminação segundo (110) pode se efetuar de tal modo que, como mostram as figs. 4,5 , e 6 , ficam eliminados dois lados de cada octógono individual. Ou então estes podem aparecer em pequena extensão (fig. 1) de modo a não destruir a resultante pseudo-simetria rômbica. A existência de finas facetas piramidais (111) nas posições esperadas no geminado (fig. 6) e as características óticas, confirmam a lei de geminação. Para maior segurança, mediu-se a ligeira variação angular entre os pinacoides (100) e (010) e prismas (110) Esta variação é igual para os dois lados to plano de geminação (fig. 6), que é também de simetria para o geminado.

São comuns os conjuntos de 4 pares de geminados, agrupados em cruz, de tal modo que se restabelesce a pseuso-simetria tetragonal, como mostra a fig. 3. A implantação na rocha se faz sempre pelo vértice cbtuso dos pares (ângulo interno de $\pm 93^{\circ} \frac{1}{2}$ ) Assim, verifica-se um desajuste angular de $\pm 14^{\circ}$ entre o primeiro e o quarto par, o que é 
compensado pelo crescimento não coplanar dos cristais, resultando as rosetas caliciformes esquematizadas na fig. 3 .

Ótica

Os índices de refração, medidos sôbre as placas cristalinas pelu método de imersão em líquidos, são os seguintes:

$$
\begin{aligned}
& \mathbf{N}_{y}=1,589 \quad( \pm 0,003) \\
& \mathbf{N}_{\mathrm{z}}=1,612( \pm 0,003)
\end{aligned}
$$

Birrefringência das placas:

$$
\mathbf{N}_{\mathrm{z}}-\mathbf{N}_{\mathrm{y}}=0,023
$$

o que indica que a espessura dos cristais isolados, não passa de 20 micra (côres cinza a amarelada ao polariscópio)

$2 \mathrm{~V}=60^{\circ}$, medido com a platina universal.

Com os dados; $\mathbf{N}_{z}, \mathbf{N}_{\mathrm{y}}$, e $2 \mathrm{~V}$, segue-se por cálculo, que:

$\mathrm{N}_{\mathrm{x}}=1,514$ e portanto

$\mathbf{N}_{\mathbf{z}}-\mathbf{N}_{\mathbf{x}}=0,098$, birrefringência máxima para a lantanita de Curitiba.

\section{Orientação;}

$$
\mathrm{a}=\mathrm{Y} ; \mathrm{b}=\mathrm{Z} ; \mathrm{c}=\mathrm{X} \text {. }
$$

Plano dos eixos óticos $\perp(001)$ e // (100) Origem:

A lantanita provém, segundo os autores, da alteração de minerais de cério. Destes, os citados na literatura são a cerita e a alanita, sôbre os quais têm-se encontrado algumas vezes, incrustações de lantanita. E possível que, nesses casos se trate de ação de águas contendo $\mathrm{CO}_{2}$ sôbre aqueles minerais. Esta reação já foi obtida em laboratório. (4).

Sjögren (8) para a ocorrência de Bethleen, Pennsilvania, considera a hipótese da precipitação em calcáreos do carbonato de terras raras, a partir de soluções sulfatadas provenientes da. alteração de veios metalíferos. Alí, a lantanita se acha associada com a calamina em calcáreo decomposto.

A precipitação se faz evidentemente sob condições superficiais, só se tendo encontrado lantanita em sólos ou rocha já alterada $(2,7,8$,). 
A ocorrência de Curitiba se encontra a menos de 3 metros da superfície do solo e as concreções calcáreas são posteriores à deposição dos sedimentos pleistocênicos, formando-se muito recentemente e provavelmente quando a rocha já começava a se decompor e desagregar, entrando no regime de formação de solos. Nessas condições, e sendo a lantanita posterior às concreções, não se pode deixar de lhe dar uma idade muito moderna.

A lantanita parece, na ocorrência, geneticamente ligada às camadas calcáreas. Só nos poucos centímetros de espessura das concreções foi ela encontrada. A subtância original que the foraeceu por alteração as terras raras, permanece incerta quanto à sua natureza e jazimento

Pode-se pensar em cuuas fontes originais, ricas em minerais de terras raras: o embasamento cristalino e o próprio sedimento pleistocênico. O embasamento cristalino é composto de gnaisses, e estes podem apresentar certa porcentagem de alanita e principalmente monazita, esparsas como accessórios. Entretanto a monazita é muito dificilmente soluvel sob condiçōes superficiais, formando como se sabe, depositos arenosos em que ela se apresenta como mineral altamente estavel. Além disso, não se encontra concentrada nos gnaisses. Muito menos a alanita.

Pgmatitos cortando o gnaisse e interrompidos na base da bacia de Curitiba poderiam apresentar minerais portadores de terras raras, resolvendo assim o problema. Mas, pelo menos citado na bibliografia, nada consta sôbre a existência de pegmatitos com aquele tipo de mineralização dos arredores de Curitiba.

Pode-se considerar ainda a hipótese de leitos mais ricos em minerais pesados nos próprios sedimentos pleistocênicos de Curitiba. Entretanto o embasamento cristalino na zona de ocorrência está há poucos metros de profundidade, e, nos cortes percorridos não observamos leitos visivelmente enriquecidos em monazita. Fica sempre a hipótese da origem descendente da lantanita, a partir de soluções que atravessassem camadas superiores, já levadas pela erosão.

Rankama e Sahama (7) admitem que o lantânio bem como algumas outras terras raras existentes como traços em sedimentos lateritizados formam soluções iônicas durante o intemperismo e, deixando o solo, infiltram-se pelos sedimentos inferiores indo substituir isomorficamente o calcio de calcáreos subjacentes. A análise espectrográfica do calcáreo da occrrência de Curitiba revela realmente traços de terras raras 
especialmente lantânio. Porém o material para análise foi retirado da mesma amostra que continha lantanita individualizada em cristais e não se poderia garantir com absoluta certeza que o material examinado não estivesse contaminado em certo grau. Suposta verdadieira a hipótese da existência de terras raras impurificando metasomáticamente o calcáreo, seria possivel pensar-se em uma ulterior eliminação das mesmas e cristalização de minerais lantaníferos em fendas.

De qualquer modo é preciso sempre admitir um processc de concentração de terras raras no próprio sólo, que é o depósito imediatamente superior às concreções.

Milton, Murata e Knechtel. (6) estudando um outro mineral secundário de terras raras (weinschenkita $-\mathrm{YPO}_{4} .2 \mathrm{H}_{2} \mathrm{O}$ ) chegaram à conclusão de ter havido uma extração contínua e demorada de ítrio do solo logo acima da ocorrência. por intermedio do sistema fascicular de plantas como a nogueira e o castanheiro. As terras raras, presentes tanto em minerais detríticos como a xenotima e monazita, como em substituições isomórficas em feld'spatos e minerais argilosos, podem, apesar de sua quantidade mínima, sob condições como as mencionadas, se concentrar nas folhas daquelas plantas. Assim, ao passo que os' sedi mentos argilosos e seus solos não contém normalmente mais que alguns milésimos porcento de óxidos de terras raras, já as cinzas das folhas de certas plantas chegam a mostrar mais de $1 \%$. Um longo periodo de quedas de folhas e uma superfície de sólo isenta de erosão são pois, condições favoraveis à uma contínua concentração de terras raras.

Para o caso especial de Curitiba, após um ciclo talvês semelhante, a laterização do solo levaria à formação de soluções ionicas que, ao atravessar o calcáreo subjacente deixariam precipitar o lantânio sob a iorma de carbonłto. Já se disse que as concreções são cortadas por numerosos filetes de manganês de origem anterior à lantanita. Como diz Milton, Murata e Knechtel, é possivel a adsorção de ions de terras raras nas superfícies livres de uma substância admissivelmente coloidal como é a psilomelana, permitindo assim uma gradual concentração, suficiente para a fixação final de lantânio em um precipitado carbonatado ccmo a lantanita.

Parece-nos este, o mecanismo mais razoavel para explicar a origem daquele raro mineral. 


\section{BIBLIOGRAFIA}

1) BLAKE, W P (1853) - On the ocurrence of crystallized carbonate of lanthanum. Am. J. Sci. 2a. s. v XVI n. ${ }^{\circ} 47$ pg. 228.

2) Dana, E. S. (1920) - A System of Mineralogy. pg. 302.

3) Ford, W E. (1932) - Dana's Textbook of Mineralogy. pg. 530.

4) Hintze, C. (1930) - Handbuch der Mineralogie. pg. 3.495.

5) MAACK, R. (1947) - Breves noticias sôbre a geologia dos estados Paraná e Santa Catarina. Arquivos de Biologia e Tecnologia do I. B. $P$ T Paraná. Vol 2. pg. 145.

6) Milton, Ch.; Murata, K. J.; Knechtel, M. M. (1944) - Weinschenkite, yttrium phosphate dihydrate, from Virginia. Am. Min. v 29, pg. 92 .

7) Rankama, K. e Sahama Th. G. (1950) - Geochemistry Chicago.

8) SJOGRen, H. J. (1912) - Doelter, Handbuch der Mineralchemie. pg. 525. 